\title{
O sonoro e o visual: questões históricas, fenomenológicas e uma abertura à estética comparada
}

\author{
Alexandre Siqueira de Freitas (USP, FAPESP, São Paulo) \\ alexandrefreitas@usp.br
}

Resumo. 0 artigo visa levantar questões relativas ao sonoro e o visual e apresentar possibilidades de abertura ao exercício da estética comparada. Na primeira parte, questões de ordem histórica revelam o interesse que o tema vem há séculos suscitando. A segunda parte discorre sobre a natureza temporal de práticas artísticas a partir de textos de artistas (Klee, Delaunay, Gould e Messiaen) e de Nattiez. A estética comparada é definida na quarta parte do artigo a partir dos conceitos de Étienne Souriau e sua abertura é apresentada através do reconhecimento da objetalidade do fato musical.

Palavras-chave: visual, sonoro, imagem musical e tempo.

The sonorous and the visual: questions concerning history, phenomenology and the exploration of compared aesthetics

Abstract. This article aims to raise questions about the sonorous and the visual and presents possibilities of ouvertures to the compared aesthetic. In the first part, questions of historical order reveal the interest this theme has provoked for centuries. The second part discusses the temporal nature of artistic practices through texts by artists (Klee, Delaunay, Gould e Messiaen) and Nattiez. The compared aesthetics is defined in the third part by the concepts of Étienne Souriau and his ouvertures are presented through the recognition of the "objetality" of the musical fact.

Keywords: visual, sonorous, musical image and time.

\section{Introdução}

Pode uma obra estritamente musical relacionar-se com a visualidade? Seria fértil buscar interferências entre sentidos diferentes? Tanto o som quanto a luz resultam de ondas vibratórias com freqüências variáveis, sujeitas a ação de intensidades variadas e caracterizadas por certa duração (MARIE, 1976, p.161).

Ao abordarmos a interação entre som e imagem nos deparamos com a dificuldade em delimitar nosso campo de pesquisa, já que são inúmeras as analogias, correlações e aproximações possíveis, além da abertura a interdisciplinaridade que o tema nos suscita.

Este artigo propõe reflexões acerca do sonoro e do visual a partir de questões históricas e questionamentos de ordem fenomenológica. A discussão sobre a objetalidade da música e a abertura para a estética comparada constitui um prolongamento das reflexões propostas em artigo publicado anteriormente na revista Música Hodie (FREITAS, 2008).
2. Interações entre Música e Artes Visuais: aspectos históricos e representações

Partindo principalmente das obras de Jean-Yves Bosseur, traçaremos algumas linhas gerais históricas de interações entre música e artes visuais com breves observações sobre a Antiguidade e seus mitos, Idade Média, Renascença, os estudos teóricos de ótica e acústica nos séculos XVII e XVIII, Romantismo, Pós-Romantismo Musical e uma alusão às representações de imagem e som na obra de Nietzsche.

Nossa primeira abordagem histórica diz respeito às representações gráficas do gesto musical, dos instrumentos na Antiguidade e dos mitos greco-romanos. Observamos, em diversos objetos do período, ilustrações que nos informam sobre o papel da música e a forma física dos instrumentos ${ }^{1}$. Não podemos demonstrar que houve uma tentativa explícita de paralelismo no gesto criativo. 0 gesto pictórico ilustrava cenas musicais e seus instrumentos com a mesma intenção da representação de um comportamento, ato de guerra ou ritual, religioso ou não. Podemos notar, entretanto, que os mitos greco-romanos exprimem relações 
de tensão e complementaridade entre os instrumentos, que são indissociáveis da vida, da educação, do culto ou da arte militar (GRAVES, 1967, p.33). 0 mito do duelo entre Mársias e Apolo, por exemplo, ilustra a tensão entre os instrumentos de corda e sopro. Marcias, considerado como extremamente hábil na arte do aulos (instrumento de sopro feito com ossos), é escalpado por Apolo por ameaçar sua soberania como instrumentista. E é graças aos mitos gregos que a música, na Antiguidade, impõe-se como fonte importante de todo ato ritual (BOSSEUR, 1998, p.11).

No princípio da Idade Média, a representação gráfica da arte musical é fortemente influenciada pelo mito da Antiguidade greco-romana e os instrumentos musicais são verdadeiros personagens que atuam segundo hierarquias e funções perfeitamente delimitadas. Os instrumentos de percussão são utilizados com desconfiança devido a associação com as bacantes. 0 caráter orgânico dos instrumentos de sopro e percussão contrabalança com o aspecto introspectivo que os instrumentos de corda podem ter (BOSSEUR, ibid., p.43). 0 aulos, tocado por Mársias, foi amaldiçoado por Atenas, devido às transformações na fisionomia dos instrumentistas (GRAVES, ibid., p.67). A arte musical era situada entre as Artes Liberais ${ }^{2}$ e a audição era considerada superior e de que caráter mais nobre que a visão (COSTA, 2006, p.132). As proporções que regem a ordem musical se encontram em múltiplos níveis da manifestação universal e mesmo no movimento dos planetas. Em vitrais, pias batismais e na arquitetura de mosteiros encontram-se analogias com escalas e organizações musicais.

Na medida em que se ampliam as funções musicais e novos instrumentos são criados, a representação plástica da música também se diversifica. A partir do final da Idade Média e da Renascença multiplicam-se imensamente as telas inspiradas na arte musical (BOSSEUR, ibid., p.85). Os pintores vão além do aspecto plástico de uma cena procurando captar, através do olhar e do gesto dos personagens, sentimentos e intenções musicais do gesto do intérprete e do compositor. As representações visuais se diversificam com essa ampliação das funções musicais e das artes na sociedade ${ }^{3}$. As capas de partituras e os instrumentos prestam-se frequentemente como suportes para expressão plástica, como é o caso dos órgãos e do cravo.

A história nos mostra também algumas tentativas de aproximação entre as duas artes, baseadas no estudo científico de ótica e acústica ${ }^{4}$. No século XVI, Arcimboldo tinha concebido um sistema de equivalências do branco ao preto e as alturas sonoras. Ele relacionava os intervalos musicais com cores, baseando-se em estudos físicos das vibrações sonoras (BOSSEUR, ibid., p.88-90). Michael Maier, alquimista, médico e filósofo, no seu livro Atalante fugitive, publicado em 1617, apresenta 50 fugas que devem ser escutadas, vistas, lidas, meditadas, julgadas e cantadas ${ }^{5}$. Em toda obra são feitas analogias entre formas físicas e procedimentos musicais como cânon, retrogradações e inversões. Em 1725, o matemático jesuita Louis Bertrand Castel concebe, depois de trinta anos de estudo, um "Cravo para os olhos com a arte de pintar os sons e todo tipo de peças musicais" (BOSSEUR, ibid.,p.90) ${ }^{6}$. A partir de um mecanismo de espelho e luzes, eram projetadas cores e sons quando acionadas as teclas do órgão. Trata-se de uma tentativa de "tornar visível" o som através de associações, que não são claramente explicadas, entre as cores e as alturas musicais.

É somente a partir do Romantismo musical que esse diálogo entre as duas artes se torna mais efetivo, já que os artistas foram levados por um impulso que incitou uma espécie de retorno à unidade original da criação artística e a se interrogar claramente sobre a analogia das sensações visuais e sonoras (BOSSEUR, ibid., p.146). Schumann, em uma carta de 1833, compara o som a uma luz que ressoa, Chopin declara a Delacroix que enxerga sua nota favorita, o sol, em azul e Liszt comenta inúmeras equivalências musicais e pictóricas que ele encontra em diversos artistas e que ele busca em sua obra (BOSSEUR, ibid., p161).

Uma outra perspectiva das relações entre artes visuais e música é apresentada por Nietzsche quando ele aborda o mito de Apolo e Dionísio. 0 impulso apolíneo constitui a nitidez dos limites e vivacidade da coloração. A partir desses impulsos, uma realidade à parte, plena de beleza, se constrói na psique humana, fazendo de cada pessoa um artista consumado e individualizado graças aos contornos como cada um delimita seus objetos representados. 0 impulso dionisíaco atua como contrapartida do apolíneo no sentido de exercer sobre os seres humanos, que um dia se individualizaram e se separaram da totalidade originária, uma força que procura recapturá-los para 0 seu estado anterior de indistinção em relação ao todo. Para Nietzsche, Apolo representaria a imagem e Dionísio, o som (DUARTE, 1994, p.74). Em seu livro "Sobre verdades e mentiras no sentido extra-moral" Nietzsche define "metáfora" como sendo verdades enfatizadas, transpostas e enfeitadas poética e retoricamente e expõe da seguinte maneira a gênese do som: "Um estímulo nervoso é primeiramente transposto em uma imagem! Primeira metáfora. A imagem é transformada em um som! Segunda metáfora" (NIETZSCHE, 1996, p.55).

Influenciado pelas idéias de Nietzsche, que exaltava a arte como única alternativa aceitável para o sofrimento, e pela teosofia, com seu ideário panteísta que pretende unir Ciência, Religião e Filosofia, o compositor russo Alexander Skryabin se convenceu de que a arte, sobretudo a música, tinha um objetivo espiritual para cujo desvendamento todos os sentidos do homem deviam reunir-se (RIBEIRO, 2005, p.394). Com base nisso, Skryabin integra em seu poema sinfônico Prometeu, o chamado "teclado de cores", que ao invés de sons, produz luminosidades coloridas que inundam o palco e se baseiam em um sistema de equivalência associados ao ciclo de quintas começar pelo Dó.7 Pouco antes de morrer, ele projetava uma obra que integraria sons, luzes, odores e contatos físicos e que se chamaria Mysterium. A obra de Skryabin pode ser 
considerada como o ponto de exacerbação culminante do pós-romantismo musical (RIBEIRO, ibidem, p.392).

Sob um ponto de vista histórico, os artistas plásticos, de uma maneira geral, parecem ter se projetado mais efetivamente no universo da música que os compositores naquele das artes plásticas (BOSSEUR, 1999, p.161). A música e as artes visuais, apesar de serem de naturezas distintas e de se dirigirem para diferentes sentidos, sempre deram margem para uma aproximação que pode ser espontânea, consciente ou mesmo científica. Além das diversas atitudes estéticas dos compositores e pintores, coexistem os múltiplos ângulos de abordagem, análise e interpretações. Isso nos leva crer que uma reflexão do aspecto plástico por parte do músico ou compositor pode gerar uma infinidade de sugestões estéticas, idéias e inspiração para o gesto composicional ou interpretativo.

\section{0 tempo e a conjunção das artes}

0 conceito de tempo na música, assim como nas artes visuais, pode ser abordado sob diferentes perspectivas. Ele suscita alguns posicionamentos por parte dos artistas e diversas indagações e relações são possiveis. Artistas plásticos, músicos e estudiosos de diversos períodos refletiram em algum momento sobre questões temporais. Vejamos como alguns deles se posicionam em relação ao tempo e como ele poderia representar um elemento que, ao mesmo tempo separa e une as duas artes.

Robert Delaunay e Paul Klee proclamaram igualmente a supremacia da visão sobre a audição quanto se trata de relação temporal. 0 pintor francês acreditava que a audição pressupusesse uma idéia de sucessão, que, por se limitar a duração, perde em profundidade em relação à visão (BOSSEUR, ibid., p.50). Assim, a percepção do universo só se completa com a visão. Klee, por sua vez, destaca a vantagem que tem uma pintura de não ter começo nem fim e assim nos deixar livres para nos abandonar em infinitas releituras e na multiplicidade de significados (BOSSEUR, ibid., p.50). Klee acreditava e era coerente com a idéia de que o artista deveria possuir uma ampla cultura sobre todas as artes e que ele deveria estar em busca do "conteúdo da verdade" em sua obra. "Um artista precisa ser tudo: poeta, pesquisador da natureza, filósofo" 8 (KLEE, 1987, p.14).

Sob o aspecto observado até então, a música é essencialmente temporal. Entretanto ela pode se espelhar ou se opor a outras concepções gerais do tempo (NATTIEZ, 2005, p.9). Jean-Jacques Nattiez em "0 Combate entre Cronos e Orfeu", reúne seus artigos que refletem sobre a arte musical e o tempo, representados pelos personagens mitológicos Orfeu e Cronos respectivamente. 0 autor apresenta diversas aproximações entre música e tempo e entre elas, uma sobre a obra de Glenn Gould ${ }^{9}$ (seus escritos e atitudes estéticas). Para Gould, a execução musical começa com uma imagem musical. 0 pensamento vem em primeiro lugar e é um fenômeno atemporal, espacial e não ordenado (NATTIEZ, ibid., p.98). Só depois que ele se encarnará em formas simbólicas lineares. 0 posicionamento estético defendido pelo pianista baseiase em uma profunda análise do texto musical e em uma "compreensão total da estrutura" (NATIEZ, ibid., p.100) para conferir assim um sentido à música. A busca da totalidade de Gould revela sua preocupação estruturalista e com aspecto atemporal da música.

Klee, Nattiez e Gould, em algum momento de suas obras escritas, fizeram alusão à polifonia, sobretudo a fuga. Suas observações sobre tratamento polifônico de uma fuga podem nos auxiliar na relativização da noção de tempo. Gould, através de seus textos e performances, demonstra uma forte afinidade pela escritura contrapontística e ele se exprime nos seguintes termos:

A fuga suscita uma curiosidade primordial, que busca descobrir relações de pergunta e resposta, desafio e réplica, chamado e eco, os segredos daqueles lugares serenos e ermos que detém as chaves do destino do homem, mas que são anteriores a toda lembrança de sua imaginação criativa (apud NATTIEZ, ibid., p.101).

Paul KLEE (ibid., p.25) buscou correspondências e a plasticidade de conceitos musicais em diversas obras ${ }^{10}$. No que diz a respeito do aspecto polifônico musical e sua transposição plástica, ele se exprimiu da seguinte maneira:

Existe realmente uma polifonia na música. A tentativa de transposição dessa essência para o campo plástico não seria em si nada demais. Mas, criar, na música, através do reconhecimento da particularidade da obra de arte polifônica, penetrando profundamente nesta esfera cósmica, a fim de emergir dela como um observador de arte transformando e então experimentar essas coisas na pintura, isso já é melhor. Pois não apenas na música pode existir a simultaneidade de vários temas independentes, assim como todas as coisas típicas que não são válidas apenas em um lugar, mas estão enraizadas, ancoradas organicamente em qualquer lugar e em toda parte.

NATTIEZ (2005, p.101) tem igualmente uma maneira própria de perceber a escrita polifônica:

É um modelo reduzido de nossa relação com o mundo. [...] a fuga estabelece analogias com certos momentos chave da vida: busca, perseguição, encontro. Todo esse movimento [...] é derivado de um material musical inicial, curto e denso, do qual tudo é tirado, esse "lugar imóvel" fora do tempo, exato e original, primitivo, denso, do qual podemos inferir todo o desenvolvimento que conduz à sua assimilação no stretto final.

Nattiez aborda explicitamente 0 aspecto extra-temporal da uma fuga. Klee, partindo da polifonia musical, aproxima artes visuais e sonoras de uma maneira ampla que vai além de um simples sistema de equivalências formais. Gould transcende a realidade na tentativa de descrever sua relação com a fuga. Observamos que os três convergem em um senso vasto de polifonia: a existência de um locus extra-temporal. Nattiez o denominou "lugar imóvel", Klee o chama de "esfera cósmica" e Gould o caracteriza como sendo "lugares serenos e ermos". Ali residiria a atemporalidade das artes.

Lévi-Strauss vai ainda mais longe crendo na irreversibilidade do tempo e na capacidade da música em suprimi-lo e imobilizá-lo. Para ele, a obra musical, apesar 
de requerer uma dimensão temporal para se manifestar, transcende o plano da linguagem articulada. Sob este aspecto, a música atua da mesma forma que o mito, ou seja, refere-se a eventos passados que se constituem como estruturas permanentes, caracterizando assim uma ambigüidade fundamental que estabelece elos entre passado, presente e futuro (LEVI-STRAUSS, 1997, p.71).

DUARTE (1994, P.78), baseando-se em Adorno, crê na antecipação de uma imagem no processo de criação musical. Para o estabelecimento do continuum musical é necessária a apropriação/criação de uma imagem. ${ }^{11}$

Uma outra relação temporal entre música e pintura pode se construir quando refletimos sobre o cravo ocular de Castel, que comentamos anteriormente. 0 ritmo das projeções de cores era conduzido diretamente pela música, construindo assim uma unidade temporal entre as duas artes, no que diz respeito à sucessão de eventos (horizontalidade do tempo). Quando projetava cores e emitia sons aproximava efetivamente as duas artes na medida em que fazia uma intima analogia entre as matérias primas: som e cor, ondas luminosas e acústicas. 0 dinamismo das imagens associase às estruturas temporais musicais e poderia criar assim uma espécie de música áudio-visual.

0 compositor francês Olivier Messiaen parece não ter dúvidas quanto à proximidade das percepções sensoriais a partir dos conceitos de tempo e espaço:

\begin{abstract}
Com efeito, a música é um diálogo perpétuo entre o espaço e o tempo, entre o som e a cor, diálogo que chega a uma unificação: o tempo é um espaço, o som é uma cor, o espaço é um complexo de tempos sobrepostos, os complexos de sons existem assim como os complexos de cores ${ }^{12}$ (apud BOSSEUR, 1998, p.122).
\end{abstract}

Comprovamos então a diversidade de abordagens que temos ao aproximarmos o sonoro, o visual e o tempo. Em uma visão estruturalista, onde os diversos elementos do tempo constroem relações de equivalência ou oposição, o aspecto atemporal da música pode revelar-se sob forma de pensamento do compositor, do intérprete e do ouvinte. A preocupação com a forma em uma obra artística nos sugere a existência de um lugar onde o tempo é suprimido e as artes se unificam e fundem. Sob esse aspecto, música e artes plásticas se aproximam em seu aspecto atemporal e a consciência das diferentes dimensões do tempo pode nos auxiliar em nossas reflexões para construção de uma interpretação e performance musical.

\section{Objetalidade da música e estética comparada}

Após refletirmos historicamente sobre analogias entre o sonoro e o visual e algumas afinidades que podemos estabelecer com questões temporais, cabe agora verificarmos de que forma o reconhecimento de relações e interferências mútuas entre as artes pode influenciar e contribuir ao entendimento, à prática interpretativa e à fruição musical.

Carl DAHLHAUS apresenta uma aproximação importante entre arte visual e sonora quando estabelece explicitamente uma relação de semelhança entre elas:
A música, de modo análogo a uma obra de arte plástica, é também objeto estético, objeto de contemplação estética. A sua objetalidade mostra-se, claro está, menos de um modo imediato do que indireto: não no instante em que ressoa, mas só quando o ouvinte, no fim de uma frase ou de um membro, se vira para o que decorreu e o representa para si como um todo consistente. A música toma ao mesmo tempo uma forma quase espacial; o que foi ouvido consolida-se em algo que está diante de nós, numa objetividade por si subsistente (1991, p.23).

E lança uma crítica aos que vêem com maus olhos o estabelecimento dessas relações:

E nada seria mais falso do que ver no impulso para a espacialização uma distorção da essência da música. Na medida em que ela é forma, alcança, falando em termos paradoxais, a sua existência verdadeira justamente no momento em que se esvai (ibid., p.24).

A aceitação da música como objeto artístico, portador de uma plasticidade, nos remete a idéia de totalidade, de quadro sonoro. Uma imagem musical constituiria esse quadro. Essa imagem seria a obra enquanto conceito e pensamento e a sintese dos sistemas de significantes resultantes de nossa capacidade analítica, de nossa vivência e das sugestões extra-musicais, como o título da obra e a biografia do compositor, por exemplo. As imagens musicais são tão variadas quanto às interpretações musicais possíveis e serão determinadas por uma compreensão analítica e sua conscientização. ${ }^{13} \mathrm{~A}$ criação contínua e a consciência dessas imagens nos abrem perspectivas que vão além das questões analíticas mais diretas e equivalências estereotipadas de som e imagem.

No momento em que a música ou uma idéia musical se esvai, ou antes que ela comece, sua existência se relaciona diferentemente com o tempo, na medida em que ela é memória ou expectação. Logo, a objetalidade parece desvincular a música de seu caráter narrativo e estreitamente submisso ao tempo.

A consciência ou a criação de nossas imagens musicais pode estar intimamente ligadas ao processo interpretativo, seja prático ou analítico. Elas serão tão variadas quanto são as percepções sensoriais de toda prática artística e especulativa. A forma musical, os sentimentos que a obra suscita, toda vivência artística ou não, vão, consequentemente, interferir na imagem musical. É dada ao intérprete a liberdade total na concepção de suas imagens. ${ }^{14}$ É importante estar consciente de que a música, como ato social, não está absolutamente imune às inúmeras interferências das outras artes e da palavra, apesar da sua relativa autonomia como expressão artística.

A reflexão sobre as possibilidades de interação ou as interferências especulativas entre as artes visuais e sonoras nos trás uma abertura à estética comparada, disciplina que Étienne SOURIAU (1969) apresenta em "La correspondance des arts: éléments d'esthétique comparée". Souriau expõe a estética comparada como sendo a disciplina que tem por base a confrontação entre obras e processos artísticos de diferentes artes. Ela coloca em evidência o que as artes podem ter em comum, o que pode se transpor de uma arte 
para outra ou as influências mútuas. Seria mais uma das ramificações da estética, delimitando de maneira explícita uma intenção comparatista.

As possiveis interseções nas poéticas ${ }^{15}$ e nas práticas artísticas que se destinam a diferentes sentidos nos incitam a ir além de comparações superficiais e a estabelecer linhas de força para uma aproximação dialética através de exercícios de estética comparada. Para a constituição desses exercícios será necessário um esforço permanente no sentido de revelar semelhanças, interferências e correspondências nas artes e forjar métodos propícios para uma aproximação analítica das estruturas dos objetos artísticos.

Entre os desafios para a realização de uma estética comparada fecunda, citamos dois:

\section{- Definição de semelhanças e diferenças:}

Observando as interferências mútuas entre artes visuais e música, verificamos, sobretudo no século $X X$, uma grande variedade de aproximações partindo dos mais diversos critérios. Cada artista que transitou entre as artes, forjou seus instrumentos e seus pressupostos. Entre as várias aproximações entre as artes visuais e sonoras citadas por BOSSEUR (1998) estão: busca por conjunções sensoriais (Kandinsky e Messiaen), interpenetração entre tempo e espaço (Kupka e Delaunay) e equivalências estruturais (Klee e Matisse). A infinidade de diálogos possíveis entre as artes representa ao mesmo tempo um grande problema e um grande desafio da estética comparada. Para o exercicio fértil da estética comparada, é necessário delimitar as relações de semelhança e paralelismo entre as artes e revelar assim os pressupostos da pesquisa. Essa delimitação implica em encontrar terminologias que sejam fiéis, ou que traduzam de maneira convincente as relações de paralelismo que possam existir entre as artes.

\section{- Adequação terminológica:}

Um dos obstáculos da consolidação da estética comparada como disciplina é o uso indiscriminado de metáforas ou figuras de linguagem, que, quando utilizadas sem real fundamentação, podem enfraquecer o caráter científico ${ }^{16}$ e podem vir a construir falsas referências terminológicas de comparação estética ou interferir nas terminologias já existentes. As impressões pessoais que resultam em metáforas acabam por escamotear observações ou julgamentos fundamentados em analogias buscadas com mais rigor e cuidado. A investigação da estética comparada busca e ressalta as semelhanças e dessemelhanças entre objetos (que se instauram como artísticos) e também visa uma maior riqueza de entendimento, fruição e contemplação dos mesmos. Incluímos também no problema terminológico o fato freqüente da literatura ou poesia predominar sobre as outras artes e atuar como elemento unificador, como acontece com grandes pensadores como Bachelard e Croce que, de acordo com SOURIAU (1969, p.11), reduziam todas as artes a observações fundadas no conhecimento da poesia. $\mathrm{Na}$ construção de um léxico reside um grande desafio da estética comparada.

A estética comparada pode ser entendida como instrumento gerador de imagens musicais, quadros sonoros que podem enriquecer a compreensão, a prática e a fruição artística.

\section{Conclusão}

Música e artes visuais têm naturezas distintas e visam diferentes percepções sensoriais. Em um primeiro momento poderiam parecer incompatíveis, porém há muitos séculos vem emergindo a consciência de um diálogo entre as artes, estimulando inúmeras indagações que podem nutrir e enriquecer ambas as partes.

Partimos de fatos históricos e discussões a cerca do fenômeno temporal das artes visuais e musicais para situarmos a estética comparada, tomada como disciplina que orientará um estudo rigoroso das aproximações artísticas.

Acreditamos que a partir do reconhecimento de uma objetalidade no fato musical, da criação contínua e da consciência de imagens musicais abriremos perspectivas que vão além das questões analíticas mais diretas e equivalências estereotipadas de som e imagem. A estética comparada pode produzir tensões férteis na busca de paralelos e transversalidade nos gestos composicionais, analíticos e da prática interpretativa.

\section{Referências}

BOSSEUR, Jean-Yves. Musique et beaux-arts: De l'Antiquité au XIXe siècle. Paris: Minerve, 1999. .Musique et arts plastiques: Interactions au XXeme siècle. Paris: Minerve, 1998.

COSTA, Ricardo da. Las definiciones de las siete artes liberales y mecánicas en la obra de Ramon Llull. Revista Anales del Seminario de Historia de la Filosofía. Madrid: Publicaciones Universidad Complutense de Madrid (UCM), vol. 23, 2006, p. 131-164.

DAHLHAUS, Carl. Estética musical. Lisboa: Edições 70, 1991.

DUARTE, Rodrigo. Som musical e reconciliação a partir de 'O nascimento da ragédia' de Nietzsche. Kriterium. Belo Horizonte: FAFICH, UFMG, vol. 35, 1994, p.74-90.

FREITAS, Alexandre Siqueira de. Diálogos entre o sonoro e o visual. Música Hodie. Goiás: Universidade Federal de Goiás, 2008, p. 29-41. 
GRAVES, Robert. Les mythes grecs. Trad. Mounir Hafez, Paris: Fayard, 1967, p.32-34.

KANDINSKY, Wassily. Do espiritual na arte. Traduzido por Álvaro Cabral e Antonio de Pádua Danesi. São Paulo: Martins Fontes, 2000.

KLEE, Paul. Sobre a arte moderna e outros ensaios. Trad. Pedro Süssekind, Rio de Janeiro: Jorge Zahar Editor, 2001.

LÉVI-STRAUSS, Claude. Olhar Escutar Ler. Trad. Beatriz Perrone-Moisés. São Paulo: Companhia das Letras, 1997.

MARIE, Jean Etienne. L'home musical. Paris: Librarie Arthaud, 1976.

NATTIEZ, Jean-Jacques. O Combate entre Cronos e Orfeu: Ensaios de semiologia musical aplicada. Trad. Luiz Paulo Sampaio.

São Paulo: Via Lettera Editora e Livraria, 2005.

NIETZSCHE, Friedrich. Sobre verdade e mentira no sentido extra-moral. In: Os pensadores, São Paulo: Editora Nova

Cultural, 1996.

PAREYSON, Luigi. Os problemas da estética. Tradução de Maria Helena Garcez. São Paulo: Martins Fontes, 1989.

RIBEIRO, José Alexandre dos Santos. Sobre os instrumentos sinfônicos e em torno deles. Rio de Janeiro: Record, 2005.

SOURIAU, Etienne. La correspondance des arts: éléments d'esthétique comparée. Paris : Flammarion, 1969.

. Vocabulaire d'esthétique. Paris : Presses Universitaires, 1990.

Alexandre Siqueira de Freitas é doutorando em Música na USP sob orientação de Eduardo Monteiro e com o projeto: "Correspondências das poéticas musicais e visuais: Os artistas do som-cor". É Mestre em Musicologia pela Universidade de Toulouse II, Le Mirail, França, pós-graduado em Prática Interpretativa pelo Conservatório Nacional de Toulouse e Bacharel em Música com habilitação em Piano pela Universidade Federal do Rio de Janeiro. Como pianista, foi vencedor do V Concurso Nacional de Piano Souza Lima e do Concurso para solistas da Orquestra Sinfônica da UFRJ e se apresentou como solista e camerista na França, Portugal, Canadá e inúmeras salas de concerto e teatros do Brasil (Fundação de Educação Artística de Belo Horizonte, Teatro Pró-Música de Juiz de Fora, Teatro Municipal de Niterói, Salão Leopoldo Miguez, sala FINEP, Fórum de Ciência e Cultura no Rio de Janeiro, entre outros espaços).

\section{Notas}

1 Entre os gregos essas representações encontravam-se mais frequentemente nos vasos, moedas e esculturas. Entre os romanos, nos afrescos, mosaicos e sarcófagos (Bosseur, ibidem, p.34).

2 As artes liberais na Idade Média são: gramática, retórica, lógica (trivium), aritmética, geometria, música e astronomia (quatrivium).

3 Concerto Campestre de Ticiano, Alegoria da Música de Fillipo Lippi, Sainta Cecília de Rafael, Concerto dos Anjos de Gaudenzio Ferrari, 0 repouso durante a fuga do Egito de Cavaragio, Vanitas de Peschier, A lição de música de Jan Vermeer, Dois meninos cantando de Franz Hals, A lição de amor de Antoine Watteau, para citar apenas alguns dos mais expressivos exemplos de telas inspiradas pela música.

4 Como prolongamento dos estudos sobre as vibrações sonoras de Pitágoras.

5 Ele diz no prefácio que seu objetivo era de unir a Ótica, a Música e a inteligência.

6 Telemann compôs algumas peças para este instrumento.

7 Dó-vermelho; Sol = alaranjado; Ré = amarelo; Lá = verde; $\mathrm{Mi}=$ azul bem claro; $\mathrm{Si}=$ igual ao mi; Fá sustenido = azul-céu; Dó bemol = azul forte; Lá bemol = violeta; $\mathrm{Mi}$ bemol = cinza aço; Si bemol = Mi bemol; Fá = marrom. (RIBEIRO, 2005, p.392).

8 Klee hesitou até os vintes anos entre a carreira de violinista ou artista plástico, tendo participado de concertos sinfônicos, inclusive como solista (KLEE, 1985, p.16).

9 Gould, além de pianista, era compositor, musicólogo, analista, escritor, sociólogo, teórico da comunicação, moralista e filósofo.

10 Como as obras "Nova Harmonia", "Quadrados em compasso ternário", "Fuga em vermelho" e "Quadro colorido em cinza maior", por exemplo.

11 Essa idéia poderia convergir com o conceito de Gould de que uma execução musical começa com uma imagem.

12 Traduzido pelo autor ; En effect, la musique est un perpêtuel dialoge entre l'espace et le temps, entre le son et la couleur, dialoge qui abouti à une unification : le Temps est un espace, le son est une couleur, l'espace est un complexe de Temps superposés, les complexes de sons existent simultanément comme complexes de couleurs".

13 A palavra "compreensão" deve ser tomada como apropriação, sua conotação do latim (com-prendre = tomar consigo) e não necessariamente como racionalização.

14 "André Breton define a criação artística como atividade absolutamente espontânea do espírito; tal atividade pode ser concebida como resultado de um treinamento sistemático e da aplicação metódica de um determinado número de receitas; contudo a obra de arte se define- e se define unicamente- por seu caráter de liberdade total" (LÉVI-STRAUSS, 1997, p.110).

15 Poética entendida a partir de sua origem etimológica poïesis, que se define como criação, formação, produção, ou seja, uma instauração do fenômeno artístico (SOURIAU, 1969, p.864).

16 Entendido como busca laboriosa e metódica de um fato por SOURIAU (1969, p.84). 